\title{
El Acuerdo de Paz y su marco juridico frente al test de sustitución constitucional y el derecho internacional humanitario*
}

Recibido: 22 de agosto del 2018 • Aprobado: 08 de noviembre del 2018

https://doi.org/10.22395/ojum.v17n35a9

Andrés Gustavo Pérez Medina*

\section{RESUMEN}

Debido al inicio de las conversaciones de paz entre el gobierno colombiano y las FARC-EP, el Congreso de la República adoptó una serie de medidas constitucionales en aras de garantizar la efectividad y el cumplimiento de los acuerdos. Las medidas consisten en actos reformatorios de la Constitución a fin de otorgarle mayor grado de seguridad jurídica. A partir de la teoría de sustitución aplicada por la Corte Constitucional, el presente artículo detalla cómo las normas de derecho internacional humanitario han sido el núcleo esencial para el examen de constitucionalidad, además de piezas interpretativas fundamentales para la adaptación del marco jurídico del Acuerdo a la carta política, sin que se sustituyan elementos definitorios fundamentales de la Constitución Política.

Palabras clave: juicio de sustitución; bloque de constitucionalidad; derecho internacional humanitario; derechos humanos; constitución.

El artículo es producto de proyectos investigativos adelantados dentro del Semillero de Investigación en Derecho Público, financiados por la Universidad Cooperativa de Colombia, sede Ibagué.

** Abogado de la Universidad Cooperativa de Colombia, Ibagué, Colombia. Investigador del Semillero de Investigación en Derecho Público de la Universidad Cooperativa de Colombia, Ibagué, Colombia. Correo electrónico: andres.perezme@ campusucc.edu.co Orcid: https://orcid.org/0000-0002-5318-7986 


\title{
The Peace Agreement and its Legal Framework Against the Constitutional Substitution Test and International Humanitarian Law
}

\begin{abstract}
Due to the beginning of peace negotiations between the Colombian government and the FARC-EP, the Congress of the Republic adopted a series of constitutional measures to guarantee the effectiveness and compliance of the agreements. The measures consist of reformatory acts of the Constitution to grant more legal security. Based on the substitution theory applied by the Constitutional Court, this paper exposes how the rules of international humanitarian law have been the essential nucleus for the constitutionality examination, as well as fundamental interpretive pieces for the legal framework adaptation of the Agreement to the Constitution, without replacing fundamental and defining elements of the Political Constitution.
\end{abstract}

Keywords: constitutional substitution test; constitutionality block; international humanitarian law; human rights; constitution.

\section{Acordo de Paz e seu contexto jurídico diante do teste de substituição constitucional e do direito internacional humanitário}

\begin{abstract}
RESUMO
Devido ao início dos diálogos de paz entre o governo colombiano e as FARC-EP, o Congresso da República adotou uma série de medidas constitucionais visando garantir a efetividade e o cumprimento dos acordos. As medidas consistem em atos reformatórios da Constituição a fim de outorgar-lhe um maior grau de segurança jurídica. A partir da teoria de substituição aplicada pela Corte Constitucional, o presente artigo detalha como as normas de direito internacional humanitário foram o núcleo essencial para o exame de constitucionalidade, além de peças interpretativas fundamentais para a adaptação do contexto jurídico do Acordo à carta política, sem que elementos decisivos fundamentais da Constituição Política sejam substituídos.

Palavras-chave: julgamento de substituição; bloco de constitucionalidade; direito internacional humanitário; direitos humanos; constituição.
\end{abstract}




\section{INTRODUCCIÓN}

A partir del 2012, con el inicio de las negociaciones entre el gobierno y las FARC-EP en Colombia, se empezó un proceso para fijar el marco normativo de tal manera que el acuerdo que surgiera de dichas negociaciones pudiera ser respetado más allá del gobierno de turno. Es decir que se buscó proteger el acuerdo mediante normas que impidieran su modificación, es allí que el derecho internacional humanitario (DIH) ha cobrado especial importancia para reformas al ordenamiento jurídico colombiano, en especial la Constitución Política. De esta manera, el Congreso de la República ha adelantado una serie de actos legislativos con el fin de dar certeza y seguridad del cumplimiento del acuerdo logrado por las partes.

Cabe resaltar que las modificaciones que se plantean con el acuerdo entre las FARC-EP y el Estado colombiano, además del aspecto normativo también suponen la adopción de políticas públicas para las víctimas del conflicto, una transformación política que actualice el sistema jurídico a unas nuevas dinámicas que posibiliten la participación de todos los actores del conflicto, modificaciones culturales y modificaciones materiales que hagan viable la efectividad del acuerdo de paz (CODHES, 2017). Sin restarle importancia a estos puntos, el presente artículo aborda en concreto el marco normativo del acuerdo, más específicamente los actos legislativos que guardan relación con el derecho internacional humanitario y su posterior estudio por parte de la Corte
Constitucional a través de la metodología del juicio de sustitución.

Si bien la Constitución Política otorga la posibilidad de que el Congreso de la República realice modificaciones mediante acto legislativo, frente a dichas reformas se ha suscitado un sinnúmero de críticas, debido a que el Congreso se estaría erigiendo como un poder constituyente, es por esto que pese a que la carta política, de manera explícita, no le otorga la posibilidad a la Corte Constitucional de estudiar dichos mecanismos de reforma, el máximo tribunal constitucional, a través de su jurisprudencia y mediante una interpretación sistemática, ha definido que no obstante que no pueda realizar un control sustancial a las reformas planteadas por el legislativo, sí le es posible apuntar vicios de procedimiento, entre ellos los vicios de competencia, cuando el Congreso exceda sus atribuciones.

De manera subsiguiente, será necesario establecer qué espacio ocupa el derecho internacional humanitario en el ordenamiento jurídico colombiano, para lo cual se debe abordar el concepto de bloque de constitucionalidad y su alcance; cabe precisar que dentro del contexto colombiano esta noción es primordialmente de índole jurisprudencial. Finalmente, producto de los diferentes actos legislativos que expidió el Congreso de la República para posibilitar el acuerdo entre el grupo armado al margen de la ley y el Estado colombiano -representado por el presidente de la república-, será preponderante determinar si estas normas expedidas por el legislativo sustituyen 
la Constitución Política. Para lo anterior se estudia el juicio de sustitución hecho por la Corte Constitucional, sus orígenes y los casos concretos abordados por el guardián de la constitución colombiana. Se hace especial referencia a las sentencias C-579 de 2013 y C-084 de 2016 en las que se discute principalmente, el marco jurídico de mayor jerarquía para el juzgamiento, tanto de miembros de las fuerzas armadas revolucionarias de Colombia como de miembros de la fuerza pública del Estado colombiano. Se parte por ende de la pregunta problema: ¿̇los actos legislativos expedidos por el Congreso de la República que buscan garantizar el Acuerdo de paz han sustituido a la Constitución Política $y$ las normas pertinentes al derecho internacional humanitario en el Estado colombiano?

El artículo consta de cuatro etapas. En primer lugar, se abordan los orígenes jurisprudenciales del juicio de sustitución en la Corte Constitucional y la metodología que empleó para el estudio de los actos legislativos. En segunda instancia, para establecer la conexión entre el derecho internacional humanitario con el juicio de sustitución, se estudia el concepto de bloque de constitucionalidad para entender cómo se integra el derecho internacional humanitario al ordenamiento jurídico colombiano y cuáles son sus alcances. El tercer aparte consta del análisis jurisprudencial de dos sentencias de la Corte Constitucional en las cuales se aplica el juicio de sustitución teniendo como eje central el derecho internacional humanitario y algunas decisiones que trastocan transversalmente la implementación del Acuerdo de Paz frente al derecho internacional. Finalmente se formulan unas conclusiones frente al test o juicio de sustitución en relación con el derecho internacional humanitario.

\section{EL JUICIO DE SUSTITUCIÓN EN LAS SENTENCIAS DE LA CORTE CONSTITUCIONAL COLOMBIANA}

A partir de la promulgación de las nuevas constituciones de mitad de siglo XX y ante los excesos cometidos por los diferentes órganos del poder estatal, en estas nuevas cartas políticas se le confirió la soberanía al pueblo, que en últimas es el máximo poder dentro del Estado y el que lo legitima. En el caso colombiano, mediante la constituyente de 1991 se expidió la norma suprema que determina las demás normas del ordenamiento jurídico (Hart, 2009), esta le asigna al pueblo la soberanía de forma exclusiva en su artículo 3.

La Constitución Política de Colombia, a pesar de ser la norma suprema del ordenamiento jurídico, no se erige como una carta invariable e inmodificable, no existen clausulas pétreas dentro del entramado constitucional; de allí que el constituyente estatuyera tres mecanismos de reforma constitucional: Asamblea Nacional Constituyente, referendo y acto legislativo. Los dos primeros los puede ejercer el pueblo de forma directa y el último se lleva a cabo a través de sus representantes, esto es, el Congreso de la República.

No obstante, la Corte Constitucional ha establecido límites al poder de reforma 
constitucional y ha impuesto parámetros al poder constituido; a la postre, el Congreso de la República, en los actos reformatorios de la Constitución, se encuentra actuando a nombre del pueblo. En este sentido, frente al poder de reforma de la Constitución, García (2016) menciona que la perdurabilidad y garantía de los preceptos normativos de orden constitucional terminan por depender de las voluntades políticas de la época. García (2016) cita a Schmitt para trazar una línea entre las diferentes normas que confluyen en una Constitución: un primer tipo de normas que representan elementos basilares de un pueblo y otras que determinan o ayudan a las primeras a su consecución, de esta manera fija los actores competentes para la reforma de cada una de ellas:

Para Schmitt, la Constitución sólo [sic] puede ser reformada en sus leyes Constitucionales. Siendo el poder de revisión un poder constituido y no soberano, no le corresponde asumir la función de establecer la Constitución que es competencia exclusiva del Poder Constituyente. Únicamente al soberano corresponde dictar la Constitución, mientras que las leyes constitucionales, como normas que sólo [sic] formalmente acompañan a las decisiones políticas fundamentales, pueden ser perfectamente modificadas por el poder constituido de revisión. (García, 2016, p. 237)

El juicio de sustitución en tanto limite al poder de reforma constitucional, tuvo una sentencia hito, la providencia C-551 de 2003 en la que la Corte Constitucional estableció diferencias entre el poder constituyente primario y secundario. Expuso que el poder constituyente primario "posee perse un poder soberano, absoluto, ilimitado, permanente, sin límites y sin control jurisdiccional, pues sus actos son político-fundacionales y no jurídicos, y cuya validez se deriva de la propia voluntad política de la sociedad" (Corte Constitucional, sentencia C-551, 2003), mientras que el poder de reforma derivado se encuentra circunscrito a la Constitución, es decir, su principal característica es que es un poder limitado.

En consonancia, si bien la Constitución no concibe cláusulas pétreas dentro de la misma, tampoco autoriza su modificación integral como sí lo disponen otras constituciones'. Sobre esta medida la Corte es clara al determinar que el poder de reforma derivado no es absoluto, ya que, si se diera la posibilidad de sustitución por parte de este, se estaría usurpando las funciones del constituyente primario y se estaría abusando de su competencia.

Empero, es de señalar que si bien la Constitución expresa que los actos reformatorios de la Constitución solo los puede estudiar la Corte Constitucional por vicios de procedimiento (ANC,1991, art. 241), el tribunal constitucional modula dicho significado y da viabilidad al estudio de estos por vicios de competencia con el fin de salvaguardar la voluntad del consti-

\footnotetext{
Se pueden mencionar las constituciones española y suiza en las cuales esto se autoriza, siempre y cuando se cumplan unos requisitos con respecto a unas mayorías calificadas.
} 
tuyente primario. Es así que en últimas, se podría decir que el test de sustitución es un límite formal, entre tanto se erige como un vicio procedimental (Tovar, 2012).

Ahora bien, la Corte Constitucional señala que no solo los preceptos contenidos en la Constitución Política son los únicos límites al poder de reforma política, sino que además se podrán tomar otros preceptos normativos que aun estando por fuera de la Constitución, por su contenido material forman parte de la misma:

[...] el juez constitucional debe analizar si la Carta fue o no sustituida por otra, para lo cual es necesario tener en cuenta los principios y valores que la Constitución contiene, y aquellos que surgen del bloque de constitucionalidad, no para revisar el contenido mismo de la reforma comparando un artículo del texto reformatorio con una regla, norma o principio constitucional - lo cual equivaldría a ejercer un control material [...] (Corte Constitucional, sentencia C-551, 2003)

Pese a la conceptualización hecha en la sentencia C-551 de 2003, la Corte Constitucional solo aplicó el test o juicio de sustitución por vez primera en la sentencia C-970 de 2004, que, como consecuencia, es la que determina la metodología para estudiar la sustitución de los actos reformatorios de la Constitución expedidos por el Congreso. Como primera medida, la obligación del accionante de identificar el elemento definitorio esencial sustituido, entendiendo que no se podrá enunciar un artículo especifico de la Constitución como parámetro de estudio, nótese que se da una semejanza frente a la teoría de Schmitt (1983) cuando expone la existencia de elementos esenciales y simples preceptos constitucionales, esta primera identificación se conoce como premisa mayor.

El segundo nivel del test supone establecer la premisa menor mediante la cual se identifican las normas jurídicas que se considera que sustituyen la carta política, para determinar así su alcance y finalmente confrontar ambas premisas y comprobar la sustitución de la premisa mayor por la premisa menor.

Con posterioridad, la Corte Constitucional estableció nuevos requerimientos para el test de sustitución que en la sentencia C-1040 de 2005 expone:

[...] (i) enunciar con suma claridad cuál es dicho elemento, (ii) señalar a partir de múltiples referentes normativos cuáles son sus especificidades en la Carta de 1991 y (iii) mostrar por qué es esencial y definitorio de la identidad de la Constitución integralmente considerada. Solo así se habrá precisado la premisa mayor del juicio de sustitución, lo cual es crucial para evitar caer en el subjetivismo judicial. Luego, se habrá de verificar si (iv) ese elemento esencial definitorio de la Constitución de 1991 es irreductible a un artículo de la Constitución, - para así evitar que éste [sic] sea transformado por la propia Corte en cláusula pétrea a partir de la cual efectúe un juicio 
de contradicción material- y si (v) la enunciación analítica de dicho elemento esencial definitorio no equivale a fijar límites materiales intocables por el poder de reforma, para así evitar que el juicio derive en un control de violación de algo supuestamente intangible, lo cual no le compete a la Corte. Una vez cumplida esta carga argumentativa por la Corte, procede determinar si dicho elemento esencial definitorio ha sido (vi) reemplazado por otro -no simplemente modificado, afectado, vulnerado o contrariado-y (vii) si el nuevo elemento esencial definitorio es opuesto o integralmente diferente, al punto que result[e] incompatible con los elementos definitorios de la identidad de la Constitución anterior. (Corte Constitucional, sentencia C- 1040, 2005)

Paralelo al juicio de sustitución, en la sentencia C-588 de 2009 se integró el test de efectividad, mediante el cual se estudia un posible manto de justificación a una decisión política, como también si el acto reformatorio beneficia a un grupo específico de personas, para por último revisar si existe sustitución de un principio fundamental a la Carta.

Ante el aumento de las causales para el estudio de actos reformatorios de la Constitución y con el fin de evitar la usurpación de funciones, esta vez del poder judicial al poder legislativo, en casos en los que se esgrime el mayor grado de legitimidad del segundo frente al primero debido a ser el máximo órgano de representación popular (Kennedy, 2010), se hizo necesario que la Corte
Constitucional acrecentara las cargas argumentativas del test.

Por lo anterior, en la sentencia C-288 de 2012, para evitar los excesos por parte del órgano judicial, la Corte enunció los siguientes mecanismos: "la cualificación de la acción pública de inconstitucionalidad, la necesidad de conservar la precisión conceptual sobre la materia y la sujeción a una metodología particular para adelantar el juicio de sustitución" (Corte Constitucional, sentencia C- 288, 2012). En este sentido, se exige una doble carga argumentativa tanto para accionante como para el juez constitucional. Finalmente, frente a este estado del arte, es de anotar que en la sentencia C-288 de 2012 la Corte reiteró que dentro de las normas pertenecientes al bloque de constitucionalidad se pueden encontrar elementos definitorios esenciales de la misma Constitución.

\section{EL BLOQUE DE CONSTITUCIONALIDAD Y EL DERECHO INTERNACIONAL HUMANITARIO}

Cuando se habla de los artículos 94 y 97 se hace expresa alusión a la noción del bloque de constitucionalidad, el cual Bidart (2006) define de la siguiente manera:
El bloque puede entenderse como un conjunto normativo que contiene disposiciones, principios o valores mate- rialmente constitucionales, fuera del texto material de la constitución y tiene como fin ser parámetro de constitucio- nalidad de las normas infra constitucionales. (p. 35) 
Ahora bien, la noción de bloque de constitucionalidad busca impedir la estaticidad de la Constitución y propugna por su actualización frente a normas de orden internacional, debido a que la Carta política responde a un momento social, histórico, económico y político particular (Gargarella, s.f). Con ello, Estrada (2012) anota que al estimar este mecanismo como medio de reajuste constitucional:

\begin{abstract}
Esta idea permitirá, inicialmente, afirmar el reconocimiento de la insuficiencia del texto constitucional, lo que obligaría a incorporar otro tipo de normas que permitan interpretar en todo momento histórico, la realidad social y económica, pues resulta pretensioso que todas las normas establecidas en el texto constitucional servirán perennemente para comprender esa realidad. (p. 56)
\end{abstract}

La Corte Constitucional colombiana adoptó el concepto de bloque de constitucionalidad en su jurisprudencia, ello también en razón al carácter material de algunas normas que de forma expresa no se encuentran en el texto constitucional, pero que por su trascendencia en los sistemas constitucionales, deben tenerse como piezas sustanciales de la carta política:

En este sentido, la noción "bloque de constitucionalidad" pretende transmitir la idea de que la constitución de un Estado es mucho más amplia que su texto constitucional, dado que existen otras disposiciones, contenidas en otros instrumentos o recopilaciones, que también son normas constitucionales. (Corte Constitucional, sentencia C-067, 2003)

Sin embargo, en Colombia el bloque de constitucionalidad ha atravesado varias etapas. Un primer periodo data de antes de la expedición de la Constitución Política de 1991 en el cual este concepto no encontraba sustento normativo y asimismo, era denegado por los jueces debido a la importancia de la soberanía nacional consagrada en la Constitución Política de 1886 en la cual solo las normas internas tenían fuerza para regir las conductas de sus asociados (Uprimny, 2005).

Por el contrario, y en un segundo momento, en la Constitución Política de 1991 se le dio gran importancia al derecho internacional, a tal punto de que se le señaló como fuente directa de la carta alrededor de todo el plexo de su articulado (artículos 53, 93, 94 y 214 de la Constitución Política).

No obstante, en un principio la Corte Constitucional aplicó normas de carácter internacional en su jurisprudencia sin hacer alusión a la noción de bloque de constitucionalidad, como en la sentencia T-426 de 1992 en la cual reconoció como derecho fundamental el mínimo vital a partir de la Declaración Universal de los Derechos Humanos y el Pacto Internacional de los Derechos Económicos, Sociales y Culturales.

A continuación, la sentencia C-225 de 1995 fue la providencia hita sobre al tema, 
dada la importancia que aduce la Corte Constitucional a la noción del bloque de constitucionalidad como criterio integrador de las normas internacionales a la Constitución. Con respecto al derecho internacional humanitario la Corte estableció:

\begin{abstract}
En tales circunstancias, la Corte Constitucional coincide con la Vista Fiscal en que el único sentido razonable que se puede conferir a la noción de prevalencia de los tratados de derechos humanos y de derecho internacional humanitario (CP art. 93 y 214 numeral $2^{\circ}$ ) es que éstos [sic] forman con el resto del texto constitucional un "bloque de constitucionalidad". (Corte Constitucional, sentencia C-225, 1995)
\end{abstract}

\subsection{Alcance del bloque de constitucionalidad y las normas del derecho internacional humanitario}

Pero, ¿qué significa que una norma de derecho internacional como lo son las normas de derecho internacional humanitario pertenezca al bloque de constitucionalidad? Es importante destacar que no todas las normas de derecho internacional se integran a la Constitución Política, de tal forma que la Corte Constitucional, en la sentencia C-358 de 1997, limita el bloque de constitucionalidad a algunos tratados internacionales cuya remisión se da de forma expresa por la Constitución Política y de tal manera rechaza la idea de que todas las normas internacionales puedan hacer de la carta:
Esto significa, si se sigue el principio que permite identificar la normatividad que conforma el bloque de constitucionalidad, que no todos los tratados internacionales forman parte de él [...] Los argumentos expuestos llevan a concluir que los tratados internacionales no constituyen por el solo hecho de serlo parte del bloque de constitucionalidad $\mathrm{y}$, por lo tanto, elemento de juicio para el examen de constitucionalidad de una norma. (Corte Constitucional, sentencia C- 358, 1997)

Con esa línea argumentativa, mediante sentencia C-582 de 1999 la Corte Constitucional destacó como únicos parámetros de constitucionalidad aquellas normas de derecho internacional que no puedan ser suspendidas bajo estados de excepción, de tal forma que con respecto al derecho internacional humanitario expuso:

En efecto, la Corte ha señalado que, salvo remisión expresa de normas superiores, sólo [sic] constituyen parámetros de control constitucional aquellos tratados y convenios internacionales que reconocen derechos humanos (i) y, que prohíben su limitación en estados de excepción (ii). Es por ello, que integran el bloque de constitucionalidad, entre otros, los tratados del derecho internacional humanitario, tales como los Convenios de Ginebra, los Protocolos I y II y ciertas normas del Pacto de San José de Costa Rica. (Corte Constitucional, sentencia C-582, 1999) 
Por último, es menester destacar que las normas de derecho internacional humanitario están al mismo nivel de la Constitución, por ello, como menciona Bobbio (2016), tendrán la función de limitar la validez de las demás normas del orden jurídico. Esto a su vez implica que sirvan como derroteros para limitar la facultad reformatoria de la Constitución Política. Así, el derecho internacional humanitario sustenta su grado de obligatoriedad al ser una norma ius cogens (Corte Constitucional, sentencia C-249, 2013), los que implica que sea referente normativo tanto para normas infraconstitucionales, como para actos reformatorios de la Constitución.

\section{JURISPRUDENCIA DE LA CORTE CONSTITUCIONAL EN LA QUE SE RELACIONAN EL JUICIO DE SUSTITUCIÓN Y LAS NORMAS DE DERECHO INTERNACIONAL HUMANITARIO DENTRO DEL MARCO JURIDICO PARA LA IMPLEMENTACIÓN DEL ACUERDO DE PAZ}

En el 2012 el gobierno nacional modificó transitoriamente los artículos 66 y 67 de la Constitución Política mediante el acto legislativo denominado Marco Jurídico para la Paz, con el fin de dar aplicación a mecanismos de justicia transicional. El acto legislativo fue demandado y la Corte Constitucional realizó un estudio sobre la sustitución de constitucionalidad mediante la sentencia C-579 de 2013.

El demandante sustentó que las expresiones contenidas en el artículo 1 del acto legislativo 1 de 2012, en sus expresiones "máximos", "cometidos de manera sis- temática" y "todos los" sustituyen la Constitución ya que modifican el pilar fundamental de la Constitución: proteger los derechos humanos e investigar las graves conductas atentatorias contra el derecho internacional humanitario. Es entonces cuando la Corte Constitucional resuelve que el respectivo acto reformatorio busca establecer un marco de justicia transicional. Frente a este concepto es adecuado citar a Rincón y Rodríguez (2012) para quienes:

De acuerdo con estos dos as-
pectos, la justicia transicional
se define como la forma en
que las sociedades que han
vivido pasados de totalitaris-
mo, dictadura, autoritarismo o
guerra, caracterizados por la
comisión masiva y sistemática
de graves crímenes, buscan
transitar hacia la democracia o
hacia la paz haciéndose cargo
de ese pasado y lidiando con
los efectos de esos crímenes
mediante diversos mecanismos
y/o estrategias. (p. 61)

El estudio llevó a la Corte Constitucional a advertir que la reforma no sustituía el pilar fundamental de "proteger los derechos humanos e investigar y sancionar graves violaciones al derecho internacional humanitario" sino que entrañaba "el compromiso del Estado social y democrático de proteger, respetar y garantizar los derechos de las víctimas y la sociedad" con sus respectivas obligaciones. Con ello, modificó el elemento definitorio esencial que había esgrimido el accionante en la demanda (Corte Constitucional, sentencia C-579, 2012). 
Así mismo, la Corte identificó como elementos del Marco Jurídico para la Paz: criterios de selección para autores de violaciones de derechos humanos, la renuncia condicionada a la acción penal y la suspensión condicionada de la pena mediante diferentes mecanismos normativos. Por tanto, dentro del proceso metodológico se estableció, como premisa mayor, el compromiso de garantía de los derechos de las víctimas y la sociedad junto con sus conexos derechos; mientras como premisa menor se incluyó la búsqueda de la paz y los medios antes planteados para su consecución.

De esta forma, la Corte Constitucional acudió a la ponderación para determinar una posible sustitución constitucional, procedimiento novedoso dentro de la jurisprudencia del máximo tribunal. El alto tribunal afirmó:

A partir de lo anterior, es posible concluir que los componentes del deber de garantía de los derechos, específicamente del compromiso de investigación, juzgamiento y en su caso sanción de las graves violaciones a los derechos humanos y al Derecho Internacional Humanitario, puede sufrir limitaciones en un ejercicio de ponderación, cuando ellas resulten en ganancias mayores en términos de otros principios constitucionales como la obtención de la paz y la construcción de la verdad en un contexto de conflicto. (Corte Constitucional, sentencia C-579, 2013)
Cabe recalcar que las normas de derecho internacional humanitario permiten la concesión de amnistías y mecanismos de justicia transicional ${ }^{2}$, sin embargo, la Corte Constitucional moduló su fallo al indicar que el acto legislativo no podrá implicar la no investigación de delitos de lesa humanidad, genocidio y crímenes de guerra perpetrados por quienes cumplieron un papel vital para la comisión de los mismos, de allí que para el alto tribunal no exista sustitución constitucional por la implantación de un régimen de justicia transicional. La Corte señaló además que el Congreso deberá ser respetuoso de las indicaciones dadas en esta sentencia para la garantía de los derechos humanos y las normas del derecho internacional humanitario.

Asimismo, se debe meditar sobre la manera en que la aplicación de la ponderación dentro del test de sustitución a prima facie parece una contradicción con la esencia misma del juicio, que es la sustitución o no de un elemento definitorio esencial sin posibilidades de conciliar. Lo anterior lleva a plantear un posible quebranto del principio democrático. En este sentido, Bernal (2007) expresó, sobre García (2005):

\footnotetext{
El Comité Internacional de la Cruz Roja, en su norma consuetudinaria 159 señala: "[c]cuando hayan cesado las hostilidades, las autoridades en el poder se esforzarán por conceder la amnistía más amplia posible a quienes hayan participado en un conflicto armado no internacional o a las personas privadas de libertad por razones relacionadas con el conflicto armado, salvo a las personas sospechosas o acusadas de haber cometido crímenes de guerra, o que estén condenadas por ello" (Henckaerts, 2005).
} 
De este modo, y como un efecto perverso, la ponderación permite que las elecciones verdaderamente determinantes de las decisiones de estos tribunales permanezcan sin fundamentar. Además, da apariencia de legitimidad a un activismo judicial que a todas luces resulta violatorio de las competencias del legislador y de la Jurisdicción Ordinaria e incompatible con la democracia y el Estado de derecho. (p. 296)

Para evitar una posible usurpación de funciones conforme a los principios de interpretación de unidad constitucional ${ }^{3} \mathrm{y}$ corrección funcional ${ }^{4}$, la sentencia previa constituye el primer juicio de sustitución en el cual la Corte Constitucional hace uso de su función interpretativa para conciliar los principios puestos en contra en el test (Robledo y Ramírez, 2014), además dicha interpretación integra ${ }^{5}$ al acto legislativo

3 "Dicho principio ha de entenderse en el sentido de que una disposición constitucional no puede ser considerada de forma aislada, ni puede ser interpretada exclusivamente a partir de ella misma, pues se halla en una conexión de sentido con los restantes preceptos constitucionales, pues la Constitución representa una unidad interna. Este principio busca que todas las normas constitucionales sean interpretadas de tal manera que se eviten contradicciones entre ellas" (Figueroa, 2010, s.p).

4 "Con este principio se pretende no desvirtuar la distribución de funciones y el equilibrio entre los poderes del Estado diseñado por la Constitución. Esto es aplicable, entre otras, a las relaciones entre legislador y juez de constitucionalidad, puesto que a la jurisdicción constitucional sólo [sic] le corresponde, frente al legislador, una función de control, por lo que le está vedada una interpretación que conduzca a una restricción de la libertad conformadora del legislador más allá de los límites establecidos por la Constitución o, incluso, a una conformación llevada a cabo por el juez mismo" (Figueroa, 2010, s.p.).

5 De cara a las sentencias aditivas o integradoras, Olano (2004) dice "Son aquellas que declaran la ilegitimidad constitucional de la previsión omitida que debería haber sido prevista por la ley para que ésta [sic] fuera el respeto por el derecho de la víctimas, decisión que permite la búsqueda de una paz estable y duradera, sin desconocer los derechos de la víctimas del conflicto, como a su vez delimita el accionar del Congreso en la expedición de las leyes estatutarias que regulen el marco de justicia transicional.

Por último, la anterior modulación del fallo se reitera en otras sentencias que se avocan al conocimiento de normas que regulan los acuerdos de paz, esto con el fin de garantizar su implementación como el cumplimiento de estándares constitucionales e internacionales.

\section{I La complementariedad de los derechos humanos y el derecho internacional humanitario}

En 2015, con motivo del Acuerdo de Paz y con el fin de delimitar el juzgamiento de todos los actores en el conflicto armado colombiano, el Congreso de la República expidió el acto legislativo numero 1 por el cual modificó el fuero penal militar. Indudablemente, con esta norma el Congreso de la República pretendió delimitar la competencia de las cortes marciales, por lo que se instituyeron, dentro de su competencia, los delitos de genocidio, lesa humanidad y crímenes de guerra para su conocimiento, además dentro de su exposición de motivos, buscó que se sancionaran y aplicaran las normas del

constitucional. En estas sentencias, la Corte no anula la disposición acusada, pero le agrega un contenido que la hace constitucional. Se incorpora un elemento nuevo al enunciado normativo, extendiendo la norma para que asuma un supuesto de hecho no contemplado en sus inicios. (p. 578) 
derecho internacional humanitario en la jurisdicción penal militar.

\section{La Corte Constitucional procedió al} estudio del anterior acto legislativo en la sentencia C-084 de 2016, donde el accionante propuso el test de sustitución sustentado en normas contenidas en el bloque de constitucionalidad y de forma directa en la Constitución, estableciendo en la demanda, como elementos definitorios esenciales subvertidos: 1) el deber del Estado de investigar y sancionar las infracciones a los derechos humanos y al derecho internacional humanitario para dar aplicación de forma complementaria a las normas del derecho internacional de los derechos humanos y el derecho internacional humanitario; 2) la independencia y la autonomía judicial; y 3) la violación del principio de que la ley no debe otorgar beneficios injustificados (Corte Constitucional, sentencia C-084, 2016).

En este sentido, para el accionante el Estado siempre deberá investigar y sancionar tanto las graves violaciones al derecho internacional humanitario como aquellas al derecho internacional de los derechos humanos, estas últimas no incluidas dentro del acto legislativo. Asimismo, el acto reformatorio implica una coacción para el juez ya que no podrá aplicar normas de derechos humanos, y como último argumento: la impunidad frente a la comisión de conductas atentatorias contra estos estándares termina por otorgar un beneficio injustificado a los miembros de la fuerza pública.
Así las cosas, la premisa mayor es fruto de la interpretación sistemática de las normas sobre derechos humanos y derecho internacional humanitario pertenecientes al bloque de constitucionalidad. Lo último con razón a que desde el protocolo 1 adicional al Convenio de Ginebra se observa una complementariedad entre derechos humanos y derecho internacional humanitario:

\section{[...] las disposiciones de esta Sección [se refiere a la Sección III del Protocolol completan las normas relativas a la protección humanitaria de las personas civiles y de los bienes de carácter civil en poder de una Parte en conflicto enunciadas en el IV Convenio, en particular en sus Títulos I y III, así como las demás normas aplicables de derecho internacional referentes a la pro- tección de los derechos huma- nos fundamentales durante los conflictos armados de carácter internacional. (ICRC, 1977, art. 72)}

Es así que al proceder a realizar el test de sustitución, la Corte Constitucional, en virtud de los principios de conservación del derecho y de armonización de la Carta, consideró que el acto reformatorio conforme al primer elemento esencial enunciado no podrá significar la negación de la protección de los derechos humanos ${ }^{6}$, dado que de la interpretación

6 la Corte Constitucional moduló su fallo profiriendo una sentencia interpretativa con acogimiento o rechazo. Olano (2004) afirma lo siguiente frente a este tipo de sentencias: "Estas sentencias interpretativas suponen entonces que se expulsa una interpretación de la disposición, pero se mantiene una eficacia normativa de la misma, es decir, si una de las interpretaciones es contraria a la Constitución y la otra resulte conforme 
sistemática de la Constitución y el bloque de constitucionalidad, no podrá hacerse tal exclusión:

Como quedó establecido en los fundamentos 92 a 108 de esta sentencia en los que se analiza el alcance de la reforma (premisa menor), la aplicación del derecho internacional humanitario en las investigaciones y juzgamientos que se adelanten contra miembros de la fuerza pública por conductas punibles relacionadas con el conflicto armado, no excluye la aplicación del derecho internacional de los derechos humanos, en virtud del poder irradiador que tienen los principios y preceptos del bloque de constitucionalidad sobre la aplicación e interpretación de los textos legales, y del carácter complementario y convergente que caracteriza a estos dos cuerpos normativos. (Corte Constitucional, sentencia C-084, 2016)

Pese a lo resuelto, se disiente frente a la posición adoptada por la Corte Constitucional, ya que por la importancia de los delitos regulados por el derecho internacional humanitario, en ninguna circunstancia podrían ser considerados actos de servicio, ya que su comisión rompe con el hilo propio de la función debido a su nivel de crueldad, naturaleza y gravedad. De tal manera, se concuerda con lo que expresó el magistrado Palacio en su salvamento de voto:

Los delitos contra el Derecho Internacional Humanitario debido a sus características, especial cruel-

con ella, el Tribunal Constitucional no puede declarar la inconstitucionalidad de la disposición, sino sólo [sic] del sentido interpretativo que colisiona con ella." (p. 577) dad, gravedad y naturaleza, desde antaño han estado absolutamente desligados de las funciones institucionales de las fuerzas armadas.

\section{(...)}

Teniendo en cuenta lo anterior, no comprendo cómo para la postura mayoritaria de la Corte, no se sustituyó un eje fundante de la Constitución de 1991 con el Acto Legislativo 01 de 2015, si es claro que esta reforma tácitamente amplió la competencia de los delitos que serían de conocimiento por parte los jueces y magistrados de la justicia penal militar (cuando se cometieran en servicio activo y en relación con el mismo) para incluir las infracciones contra el Derecho Internacional Humanitario en su esfera de conocimiento. (Corte Constitucional, sentencia C-084, 2016)

Cabe anotar como por segunda vez en un test de sustitución, el tribunal constitucional colombiano emitió una sentencia de carácter modulativo. Ambas sentencias se relacionan por el hecho de que presentan aspectos normativos del derecho internacional humanitario y se acude a criterios hermenéuticos sistemáticos que consultan la noción del bloque de constitucionalidad y sustraen la aplicación exclusiva de un método interpretativo literal (Cajas, 2007).

\subsection{Algunos referentes jurisprudenciales frente a la implementación del Acuerdos de Paz y su relación con el derecho internacional humanitario}

Una vez firmado el Acuerdo de Paz, conviene señalar que para el desarrollo 
de todo el marco constitucional en la implementación del Acuerdo de Paz, el Congreso de la República profirió el acto legislativo 1 de 2016, con el cual creó un procedimiento especial de reforma constitucional que contemplaba mecanismos más agiles para la expedición de actos reformatorios posteriores, además de que asignaba facultades normativas al presidente de la República.

Es así como la Corte Constitucional, mediante sentencia C-699 de 2016 procedió al estudio inicial de una posible sustitución constitucional del elemento definitorio esencial del principio de rigidez específica. Ante la premisa mayor expuesta, la Corte negó una posible sustitución, adujo el fin que prevé el acto de reforma constitucional, ello es, la consecución de la paz como principio cardinal de la Constitución Política, además del carácter transitorio y excepcional de la reforma. En palabras del alto tribunal:

Esto significa que la resistencia al cambio de las normas constitucionales debe ciertamente ser superior a la de las leyes, pero el grado de superioridad es un aspecto susceptible de adaptación transicional, precisamente como una forma de garantizar la integridad de la parte dogmática de la Carta, y en particular el derecho a la paz y los demás derechos y principios que dependen de ella (CP art. 22 y concordantes). Pues bien, en este caso eso quiere decir que en ejercicio del poder de reforma se podían adaptar para la transición, dentro de los límites de competencia indicados al enunciar la premisa mayor, las exigencias procedimentales para el cambio constitucional con el fin de garantizar una transición apropiada hacia el fin del conflicto, y en última instancia la paz. (cursiva dentro del texto y subrayado fuera del texto) (Corte Constitucional, Sentencia C-699 de 2016).

En un segundo momento y frente a una posible sustitución del principio de separación de poderes por las competencias conferidas al presidente de la República, el tribunal indicó la constitucionalidad del acto y afirmó la no sustitución del elemento definitorio esencial, sustentándose en lo siguiente:

La habilitación está, como se dijo, temporalmente limitada y su ejercicio es transitorio. Puede ejercerse por un término de 180 días, y se funda en normas de la Constitución que buscan asegurar la transición hacia el fin del conflicto. Los decretos ley que se expidan con arreglo a estas facultades extraordinarias deben facilitar o asegurar el desarrollo normativo del acuerdo final, y no pueden versar sobre ciertas materias con reserva especial o estricta de ley. Es cierto que al perfeccionarse el Acto Legislativo 1 de 2016, no se había finiquitado un acuerdo final, pero eso no quiere decir que las facultades carezcan de límites competenciales, sino que los límites competenciales se concretaron después o al expedirse la reforma (...) (subrayado fuera del texto) (Corte Constitucional, sentencia C-699 de 2016) 
Otro punto importante del acto legislativo fue que en su artículo 4 denominó el Acuerdo de Paz como "un acuerdo especial en los términos del artículo 3 común a los convenios de Ginebra", de forma que el acuerdo pasaba entonces a ser incorporado directamente al bloque de constitucionalidad. La norma fue objeto de demanda por sustitución constitucional del elemento esencial del bloque de constitucionalidad. No obstante, en sentencia C-332 de 2017 la Corte Constitucional se declaró inhibida en razón a que tal pertenencia fue cercenada mediante el acto legislativo 2 de 2016. Pese a esto, conviene citar el salvamento de voto del magistrado Linares en tanto considera que en escenarios de justicia transicional la rigidez constitucional debería ser menor al aplicar el juicio de sustitución, tesis que se refrendó en la sentencia C-544 de 2017:

\begin{abstract}
Asimismo, en un contexto de justicia transicional, cuando resulte justificado, la Corte Constitucional puede flexibilizar la intensidad de su control en lo que concierne a la fiabilidad de las consideraciones empíricas asociadas a la idoneidad y necesidad de las medidas transicionales. En este sentido, el Legislador transicional disfruta de un margen de acción que, aunque no es ilimitado, sí le otorga una competencia más amplia para elegir entre los diversos medios alternativos disponibles para conseguir los fines de la transición. (Corte Constitucional, sentencia C-554 de 2017)
\end{abstract}

En las sucesivas demandas de constitucionalidad, tanto de actos legislativos como de normas infraconstitucionales para la implementación del Acuerdo de Paz, la Corte Constitucional denotó una flexibilización de los presupuestos para su estudio, todo en aras de la consecución de la paz como fin mismo y máximo del Estado social de derecho.

Hecha la anotación frente a la flexibilidad de las posteriores demandas de inconstitucionalidad y para retomar la naturaleza del Acuerdo de Paz, se anota que igualmente, el Fiscal General de la Nación de la época interpuso demanda de inconstitucionalidad para que se le diera el estatus de acuerdo especial al Acuerdo de Paz conforme a las normas del derecho internacional humanitario. Mediante sentencia C-171 de $2017^{7}$ la Corte Constitucional procedió al estudio de constitucionalidad, pero terminó inhibida por falta de requisitos formales de la demanda, en razón a la ausencia de los requisitos de certeza y suficiencia para su estudio.

Por ello, dentro del plano nacional e internacional aún se discute la categorización de los acuerdos de paz dentro del ordenamiento jurídico. Sin embargo, se considera que, por la propia naturaleza del acuerdo, este debería ser visto como una norma perteneciente al bloque de constitucionalidad al conferírsele el tratamiento de acuerdo especial de cara a las normas del derecho internacional humanitario, al tener en cuenta las

\footnotetext{
Se debe apuntar que esta sentencia se profirió con anterioridad a la sentencia C-332 de 2017, pero para efectos prácticos del trabajo se abordó con posterioridad, en consonancia con las consideraciones expuestas en cada una.
} 
siguientes razones:

Por otro lado, está aquella posición que expresa que los elementos del Acuerdo Final destinados a superar las causas del conflicto armado pretenden no solo acabar con las hostilidades sino evitar que la violencia armada surja de nuevo. De esta forma, las medidas en materia de tierras o solución del asunto de las drogas ilícitas, al buscar una paz estable, estarían orientadas al fin último del DIH, es decir, a evitar el impacto humanitario que produce el conflicto armado. Por ello, el Acuerdo Final en su conjunto se podría considerar como acuerdo especial. (Amaya y Guzmán, 2017, p. 56)

En efecto, un pronunciamiento sobre la naturaleza del Acuerdo de Paz hubiera significado la delimitación de un margen interpretativo del juez constitucional para el estudio de posteriores normas que buscan desarrollar los puntos contenidos en ellos, sin lugar a duda, este supone un punto que hasta ahora no presenta claridad suficiente y que deberá ser despejado en lo sucesivo.

Una vez avalado el acto legislativo 1 de 2016, se generaron una serie de normas en virtud de garantizar la implementación normativa del Acuerdo de Paz en el ordenamiento jurídico colombiano. Por ende, se expidió el acto legislativo 1 de 2017 que se erige como el gran marco normativo para "la terminación del conflicto y la construcción de una paz estable y duradera". De esta manera y mediante sentencia C-674 de 2017, la Corte Consti- tucional procedió al respectivo estudio de constitucionalidad del acto reformatorio.

Empero, corresponde hacer un especial énfasis en que el acto de reforma referido determinó la creación de una jurisdicción especial dentro del marco de justicia transicional, para investigar, perseguir y sancionar los hechos ocurridos en el marco del conflicto interno, al ver la institucionalidad como una pieza del conflicto que no podía garantizar la imparcialidad dentro del juzgamiento (Franco, 2017).

Igualmente, además de la creación de la Jurisdicción Especial para la Paz, el acto reformatorio también contempló un Sistema Integral de Verdad, Justicia, Reparación y no Repetición, que tuvo en cuenta toda una línea jurisprudencial del conflicto armado. Lo anterior, mediante la interpretación de los instrumentos del derecho internacional humanitario y la Constitución, en tanto, estos últimos se erigen como obligaciones estatales de carácter irrenunciable, aún en la aplicación de mecanismos de justicia transicional (Ospina, Linares y Maldonado, 2017).

Frente a estos dos puntos centrales del acto legislativo, la Corte Constitucional realizó un extenso examen frente a la constitucionalidad de la norma y aplicó el test de sustitución. Así conviene explicitar que del cotejo del acto reformatorio con las normas de derecho internacional humanitario, el tribunal constitucional colombiano declaró la constitucionalidad del acto reformatorio y en consecuencia, la no sustitución del elemento defini- 
torio esencial del deber del Estado de investigar, juzgar y sancionar las graves violaciones a los derechos humanos y el derecho internacional humanitario:

En este contexto, la Sala concluyó que el modelo sancionatorio previsto en el Acto Legislativo 01 de 2017 no desconoce el deber del Estado de investigar, juzgar y sancionar las graves violaciones a los derechos humanos y las infracciones al Derecho Internacional Humanitario, por dos razones fundamentales. Primero, porque justamente la reforma constitucional preserva expresamente el deber de criminalizar a los máximos responsables de los delitos de lesa humanidad, genocidio y crímenes de guerra, y únicamente permite la renuncia a la persecución de los delitos que no tienen esta connotación. Y adicionalmente, porque la renuncia a la persecución penal y el acceso y la conservación de los tratamientos penales especiales se encuentra supeditada al cumplimiento de las exigencias inherentes al sistema de verdad, justicia, reparación y no repetición, establecidas en función del sistema de condicionalidades. (subrayado fuera del texto) (Corte Constitucional, sentencia C-674, 2017)

Finalmente, otro referente jurisprudencial importante es la sentencia C-007 de 2018, en la cual se examinó la Ley 1820 de 2016, puesto que, en virtud del procedimiento legislativo especial para la paz, en esta "se dictan disposiciones sobre indultos, amnistías y tratamientos especiales". Hecho él análisis, se encuentra que la Corte Constitucional, a partir del bloque de constitucionalidad y las normas del derecho internacional humanitario, declaró la inexequibilidad de la expresión "grave" contenida en el artículo 23 y el inciso final del mismo artículo, al considerar que tales expresiones normativas vulneran el principio y elemento definitorio esencial del deber que tiene el Estado de investigar y sancionar graves infracciones al derecho internacional humanitario. Al respecto, la Corte Constitucional afirmó:

\begin{abstract}
En síntesis, de acuerdo con la jurisprudencia reseñada y el derecho internacional humanitario, el deber de investigar, esclarecer, perseguir y sancionar las graves infracciones al DIH, está referido a todos los crímenes de guerra, sin que exista en esa normatividad internacional una categoría o unos criterios que permitan identificar con certeza una modalidad de crimen internacional denominada "grave crimen de guerra". La jurisprudencia de la Corte ha interpretado el elemento sistemático referido a los crímenes de guerra, como la necesidad de enfatizar en que estos tengan un nexo con el conflicto armado, excluyendo así hechos aislados, desconectados del fenómeno de violencia organizada que comporta la confrontación bélica. (subrayados y cursivas dentro del texto) (Corte Constitucional, sentencia C-007, 2018)
\end{abstract}

Pese a que en este caso el alto tribunal no aplique el test de sustitución constitucional, por tratarse de una norma de carácter infraconstitucional, la decisión representa un precedente importante en la adecuación del marco jurídico 
para la implementación del Acuerdo de Paz conforme al derecho internacional humanitario.

\section{CONCLUSIONES}

Sin lugar a dudas la implementación del Acuerdo de Paz trajo consigo numerosas reformas constitucionales que aseguraran su aplicación. La Corte Constitucional, mediante la acción pública de inconstitucionalidad tuvo conocimiento sobre estos y aplicó la teoría del juicio o test de sustitución constitucional. No obstante, y pese a los múltiples requisitos esgrimidos por la Corte Constitucional para el estudio de actos legislativos con antelación a los diálogos y posterior firma del Acuerdo, el máximo tribunal constitucional flexibilizó gran parte de esos requisitos y avaló la no sustitución de la Constitución de los actos legislativos expedidos por el Congreso para el desarrollo de un marco de justicia transicional.

Frente al derecho internacional humanitario, se puede formular dos conclusiones: 1) se debe definir que el derecho internacional humanitario constituye una verdadera norma jurídica dentro del ordenamiento jurídico colombiano, la cual se encuentra en el mismo rango de la Constitución Política. Es por ello que no solo las leyes emitidas por el Congreso de la República deben ser acordes con estos preceptos normativos, sino también todos los actos reformatorios a la Constitución. De esta forma, el derecho internacional humanitario se integra al sistema jurídico colombiano mediante el bloque de constitucionalidad, inclusive al ser normas ius cogens no necesitan ser ratificadas por los Estados, al ser normas de carácter universal.

2) Por otro parte, frente a la modificación de la normatividad del derecho internacional humanitario dentro del ordenamiento jurídico, la línea jurisprudencial dirá que el derecho internacional humanitario ha sido un verdadero referente de validez, eje principal para los actos legislativos que desarrollaron la implementación del Acuerdo de Paz, igualmente que este no se ha visto modificado por dichos actos reformatorios de la Constitución. Sin embargo, cabe aclarar que han sido las demandas contra actos legislativos que tratan temas conexos al derecho internacional humanitario, las únicas en las cuales la Corte ha proferido fallos de carácter modulativo en juicios de sustitución, con lo que, a primera vista, estas reformas podrían estar en contra de los presupuestos consagrados en la Constitución y el derecho internacional humanitario. Debido a lo anterior, ha sido la Corte Constitucional la encargada de interpretar dichos actos legislativos para que se armonicen con el ordenamiento jurídico vigente, lo cual permitirá garantizar los derechos consagrados en el derecho internacional humanitario.

Por todo esto, el derecho internacional humanitario ha jugado un papel de vital importancia como criterio de interpretación y validez con respecto a todo el marco jurídico para la paz. Incluso de este se extrajo el elemento definitorio 
esencial de la obligación del Estado de garantizar los derechos de las víctimas y la obligación del Estado de investigar, juzgar y sancionar graves violaciones a los derechos humanos y al derecho internacional humanitario. Con todo, los actos legislativos estudiados han sido respetuosos de los estándares internacionales y constitucionales al aducir que la adopción de mecanismos de justicia transicional consagrados en normas del derecho internacional humanitario, siempre y cuando respeten el núcleo esencial de los derechos de las victimas, serán medios idóneos para la consecución de los fines del Estado social de derecho.

Empero, quedan pendientes algunos retos, como la definición de la Corte Constitucional de la naturaleza del Acuerdo de Paz, la puesta en práctica de la Jurisdicción Especial para la Paz, junto con las medidas en concreto para garantizar los derechos de las víctimas y el juzgamiento de los miembros de la fuerza pública por crímenes atentatorios contra el derecho internacional humanitario y los derechos humanos.

\section{REFERENCIAS}

Amaya, Á., y Guzmán, V. (2017). La naturaleza jurídico-internacional de los Acuerdos de Paz y sus consecuencias en la implementación. International Law: Revista Colombiana de Derecho Internacional, 15(30), 41-60. doi:10.11144/ Javeriana.il15-30.njia

Asamblea Nacional Constituyente (191). Constitución Política de Colombia. Bogotá: República de Colombia. Recuperado de http://www.constitucioncolombia.com/ indice.php
Bernal, C. (2007). Reputación y defensa del neoconstitucionalismo. En M. Carbonell. (Ed), Teoría del neoconstitucionalismo (pp. 289327). Madrid, España: Editorial Trotta S.A.

Bidart, G. (2006). Teoría general de los derechos humanos. Buenos Aires, Argentina: Astrea.

Bobbio, N. (2016). Teoría general del derecho. Bogotá, Colombia: Editorial Temis.

Cajas, M. (2007). Acerca de la interpretación en el control de las reformas constitucionales. Díkaion, 16, 31-47.

Consultoría para los Derechos Humanos y el Desplazamiento (CODHES) (2017). 13 propuestas para la adecuación participativa de la normativa sobre victimas al acuerdo final de paz entre las FARC-EP y el Gobierno de Colombia. Aportes para la implementación del subpunto 5.1.3.7. Papeles para la Incidencia N. ${ }^{\circ}$ 3. E. Lagos (Comp.). Colombia: CODHES. Recuperado de: https://issuu.com/codhes/ docs/trece _ propuestas

Corte Constitucional (12 de agosto de 1992). Sentencia T-492 de 1992. [MP José Gregorio Hernández].

Corte Constitucional (18 de mayo de 1995). Sentencia C-225 de 1995. [MP Alejandro Martínez Caballero].

Corte Constitucional (5 de agosto de 1997). Sentencia C- 358 de 1997. [MP Eduardo Cifuentes Muñoz].

Corte Constitucional (11 de agosto de 1999). Sentencia C-582 de 1999. [MP Alejandro Martínez Caballero].

Corte Constitucional (9 de Julio de 2003). Sentencia C-551. [MP Eduardo Montealegre Lynnet].

Corte Constitucional (4 de febrero de 2003). Sentencia C-067 de 2003. [MP Marco Gerardo Monroy Cabral. 
Corte Constitucional (7 de octubre de 2004). Sentencia C-970. [MP Rodrigo Escobar Gil].

Corte Constitucional (19 de octubre de 2005). Sentencia C-1040. [MP Manuel José Cepeda Espinoza, Rodrigo Escobar Gil, Marco Gerardo Monroy Cabra, Humberto Antonio Sierra Porto, Álvaro Tafur Galvis, Clara Inés Vargas Hernández].

Corte Constitucional (27 de agosto de 2009). Sentencia C-588 de 2009. [MP Gabriel Eduardo Mendoza Martelo].

Corte Constitucional (18 de abril de 2012). Sentencia C-288 de 2012. [MP Luís Ernesto Vargas Silva].

Corte Constitucional (29 de marzo de 2012). Sentencia C-249 de 2012. [MP Juan Carlos Henao Perez].

Corte Constitucional (24 de abril de 2013). Sentencia C-249 de 2013. [MP María Victoria Calle Correa].

Corte Constitucional (28 de agosto de 2013). Sentencia C-579 de 2013. [MP Jorge Ignacio Pretelt Chaljub].

Corte Constitucional (13 de diciembre de 2016). Sentencia C-699 de 2016 [MP María Victoria Calle Correa].

Corte Constitucional (22 de marzo de 2017). Sentencia C-171 de 2017. [MP Iván Humberto Escruceria Mayolo].

Corte Constitucional (30 de agosto de 2017). Sentencia C-554 de 2017. [MP Carlos Bernal Pulido].

Corte Constitucional (17 de mayo de 2017). Sentencia C-332 de 2017. (MP Antonio José Lizarazo Ocampo).

Corte Constitucional (14 de noviembre de 2017). Sentencia C-674 de 2017. [MP Luis Guillermo Guerrero Pérez].
Corte Constitucional (18 de marzo de 2018). Sentencia C-007 de 2018. [MP Diana Fajardo Rivera].

Estrada, S. (2011). Los principios jurídicos y el bloque de constitucionalidad. Medellín, Colombia: Universidad de Medellín.

Figueroa, G. (2010). Duplicidad interpretativa: interpretación jurídica en general e interpretación constitucional en particular. Díkaion, 19(1), s.p. Recuperado de http://dikaion. unisabana.edu.co/index.php/dikaion/article/ view/1706/2233

Franco, A. (2017). Confrontación entre las disposiciones de la Jurisdicción Especial para la Paz y las obligaciones del Estado con la ratificación del estatuto de roma (Tesis de pregrado). Universidad Católica, Bogotá, Colombia.

García, E. (2016). La sustitución de la constitución en el derecho constitucional colombiano. Revista Derecho Político, (95), 229-246. Recuperado de http://revistas.uned.es/index.php/ derechopolitico/article/view/16237

García, J. (2005). Tres sentencias del tribunal constitucional. O cuan fácil es la veracidad periodística y que liviano el honor de los particulares. Estudios de derecho, 61 (139), 101134. Recuperado de: https://aprendeenlinea. udea.edu.co/revistas/index.php/red/article/ view/332317/20788225

Gargarella, R. (s.f). El nuevo constitucionalismo latinoamericano, recuperado de: http://www. palermo.edu/Archivos content/derecho/ pdf/Constitucionalismo_ atinoamericano. $\underline{\mathrm{pdf}}$

Hart, H. (2009). El concepto del derecho. Buenos Aires, Argentina: Abeledot Perrot.

Henckaerts, J. (2005, marzo). Estudio sobre el derecho internacional humanitario consuetudinario: una contribución a la comprensión y al respeto del derecho de 
los conflictos armados. International Review of the Red Cross, 87(857), 2-46. Recuperado de https://www.icrc.org/es/doc/assets/files/ other/icrc_003_0860.pdf

International Committee of the Red Cross (ICRC). (1977). Protocolo I adicional a los Convenios de Ginebra de 1949 relativo a la protección de las víctimas de los conflictos armados internacionales. Recuperado de https://www.icrc.org/es/ document/protocolo-i-adicional-convenios-ginebra-1949-proteccion-victimasconflictos-armados-internacionales1977

Kennedy, D. (1990). Libertad y restricción en la decisión judicial. Bogotá: Editorial Universidad de los Andes.

Olano, H. (2004). Tipología de nuestras sentencias constitucionales. Vniversitas, (108), 571-602. Recuperado de http://www.redalyc. org/articulo.oa?id=82510813

Ospina, J., Linares, C., y Maldonado, J. (2017). Promoviendo la garantía y exigiendo los derechos. Bogotá: Comisión Colombiana de Juristas.
Rincón, T., y Rodríguez, J. (2012). La justicia y las atrocidades del pasado: Teoría y análisis de la justicia transicional. Madrid, España: Editorial Miguel Porrúa.

Robledo, P. y Ramírez, G. (2014). La jurisprudencia constitucional colombiana en el año 2013: el control de constitucionalidad por sustitución y el amparo reforzado a los sujetos de especial protección constitucional. Anuario Iberoamericano de Justicia Constitucional, (18), 587-620. Recuperado de https:// dialnet.unirioja.es/descarga/articulo/4900 228.pdf

Schmitt, C. (1983). La defensa de la Constitución (2 ed.). Madrid, España: Tecnos.

Tovar, F. (2012). La teoría de la sustitución constitucional y el dilema de los límites de la reforma. Principia Iuris, 18(18), 271-285. Recuperado de http://revistas.ustatunja. edu.co/index.php/piuris/article/view/509/ $\underline{629}$

Uprimny, R. (2005). El bloque de constitucionalidad. Bogotá, Colombia: Universidad Nacional de Colombia. 